\title{
Low rate of life-threatening events and limitations in predicting invasive and non-invasive markers of symptoms in a cohort of type 1 Brugada syndrome patients. Data and insights from the GenBra Registry.
}

Luciana Sacilotto $^{1}$, Mauricio Scanavacca ${ }^{2}$, Natália Olivetti ${ }^{1}$, Carolina Lemes ${ }^{1}$, Gabrielle Pessente $^{1}$, Fanny Wulkan ${ }^{1}$, Denise Hachul ${ }^{2}$, José Eduardo Krieger ${ }^{2}$, Alexandre Pereira ${ }^{2}$, and Francisco Darrieux ${ }^{2}$

${ }^{1}$ Universidade de Sao Paulo Faculdade de Medicina Hospital das Clinicas Instituto do Coracao

${ }^{2}$ Universidade de Sao Paulo Faculdade de Medicina Hospital das Clinicas Instituto do Coracao

June 15,2020

\begin{abstract}
Background: Brugada syndrome (BrS) has diagnostic challenges and controversial risk assessment. We aimed to investigate invasive and non-invasive parameters in symptomatic and asymptomatic patients from a Brazilian cohort of type- 1 BrS. Methods Patients with spontaneous and drug-induced type- $1 \mathrm{BrS}$ were classified in two groups, asymptomatic $(\mathrm{n}=116,84.1 \%)$ and symptomatic ( $\mathrm{n}=22,15.9 \%, 13$ with arrhythmogenic syncope, 9 with aborted sudden cardiac death). Genetic testing, EPS parameters, and ECG parameters were analysed. Results: 138 consecutive patients were eligible, 101 men (73.2\%), mean 41.4 years, mostly probands $(79 \%)$. Spontaneous pattern, observed in $77.5 \%$ of the patients, was associated to symptoms only if expressed in V1 and V2 standard position (not high precordial leads) $(\mathrm{p}=0.014)$. All symptomatic patients were probands. The presence of RV outflow tract conduction delay (RVOTcd) signs, positive EPS and SCN5A status was similar between symptomatic and asymptomatic subjects. During mean 75-month follow-up, 8 patients had appropriate therapies. All had spontaneous type-1 ECG pattern and 2/8 (25\%) were asymptomatic, with positive EPS. The overall LAE incidence of $1.1 \%$ year dropped to $0.27 \%$ in asymptomatic patients. RVOTcd occurred more frequently in SCN5A carriers (QRS-f $33.3 \%$ vs $7.7 \%, \mathrm{p}=0.005$; AVR sign $58.3 \%$ vs $13.6 \%$, $\mathrm{p}<0.001$; deep S in lead I $75 \%$ vs $48.5 \%, \mathrm{p}=0.025 \%$ ), as well as longer HV interval (66ms vs $49 \mathrm{~ms}, \mathrm{p}<0.001)$. Conclusions: Spontaneous type-1 Brugada pattern in standard leads and proband status were more frequent in symptomatic subjects. RVOTcd, more common in SCN5A carriers, did not predict symptoms in BrS patients. EPS exhibited limited prognostic value for this low risk population.
\end{abstract}

Low rate of life-threatening events and limitations in predicting invasive and non-invasive markers of symptoms in a cohort of type 1 Brugada syndrome patients. Data and insights from the GenBra Registry.

Brief title: Predictors of symptoms in Type-1 Brugada Patients.

Author 1: Luciana Sacilotto, MD, PhD;

Author 2: Maurício I. Scanavacca, MD, PhD;

Author 3: Natália Olivetti, MD; 
Author 4: Carolina Lemes, MD;

Author 5: Gabrielle D. Pessente, BsC, MsC;

Author 6: Fanny Wulkan, BsC, PhD;

Author 7: Denise T. Hachul, MD, PhD;

Author 8: Jose E. Krieger, MD, PhD;

Author 9: Alexandre C. Pereira, MD, PhD;

Author 10: Francisco C. C. Darrieux, MD, PhD.

From Instituto do Coração (InCor), Hospital das Clínicas HCFMUSP, Faculdade de Medicina, Universidade de São Paulo - Av. Dr. Enéas de Carvalho Aguiar, 44 - CEP 05403-010 São Paulo, Brazil.

\section{Funding:}

This study was supported by grant \#2016/15223-3 from FAPESP (Fundação de Amparo à Pesquisa do Estado de São Paulo), a research supporting foundation of the State of São Paulo, in Brazil.

\section{Disclosure Statement}

All authors have reported that they have no relationships relevant to the contents of this paper to disclose.

\section{Acknowledgements:}

The authors also express their gratitude to the post-graduation coordination team, the Laboratory of Genetics and Molecular Cardiology at Instituto do Coração (InCor) - Hospital das Clínicas da Faculdade de Medicina, Universidade de São Paulo, and Fleury Medicina e Saúde.

\section{Corresponding author:}

Francisco C. C. Darrieux, M.D., Ph.D.

Arrhythmia Unit, Instituto do Coração (InCor), Hospital das Clinicas HCFMUSP,

Faculdade de Medicina, Universidade de São Paulo

Av. Dr Eneas de Carvalho Aguiar, 44. CEP 05403-900 São Paulo, Brazil.

Phone: $+5511266153 \backslash$ sout41

Fax: +551126625312

Email:francisco.darrieux@incor.usp.br

ORCID \# 0000-0001-5818-5958

Tweet : This study intended to describe markers of symptoms in a type-1 BrS cohort and to explore its association with invasive and non-invasive markers of risk.

\section{INTRODUCTION}

Brugada syndrome $(\mathrm{BrS})$ is an inherited arrhythmogenic disorder, characterized by ST-segment elevation with typical ECG type-1 pattern in the right precordial leads and an increased risk of ventricular fibrillation (VF). ${ }^{1}$ The prevalence of $\mathrm{BrS}$ is estimated to be 1-5 per 10,000 inhabitants worldwide, but the real incidence of sudden cardiac death (SCD) in these patients remains uncertain. ${ }^{2}$ The electrocardiographic (ECG) pattern is dynamic and high precordial leads (HPL) increase $\mathrm{BrS}$ recognition. ${ }^{3}$

Recent studies have shown that the absolute risk of asymptomatic patients who develop ventricular tachycardia or fibrillation (VT/VF) might have been overestimated in the past. ${ }^{4}$ \{Casado-Arroyo, 2016, Long-Term Trends in Newly Diagnosed Brugada Syndrome: Implications for Risk Stratification\}\{Casado-Arroyo, 2016, 
Long-Term Trends in Newly Diagnosed Brugada Syndrome: Implications for Risk Stratification\}\{CasadoArroyo, 2016, Long-Term Trends in Newly Diagnosed Brugada Syndrome: Implications for Risk Stratification\}\{Milman, 2017, Age of First Arrhythmic Event in Brugada Syndrome: Data From the SABRUS (Survey on Arrhythmic Events in Brugada Syndrome) in 678 Patients\}\{Casado-Arroyo, 2016, Long-Term Trends in Newly Diagnosed Brugada Syndrome: Implications for Risk Stratification\}\{Casado-Arroyo, 2016, LongTerm Trends in Newly Diagnosed Brugada Syndrome: Implications for Risk Stratification\}Symptomatic BrS subjects who once experienced cardiac syncope or aborted SCD (aSCD) have a known high risk of VF recurrence. Currently, guidelines provide recommendations for the management of symptomatic patients. On the contrary, there is no consensus for the asymptomatic patients and the management depends on evaluation of different parameters and the decision is usually personalized. The risk stratification of these patients has still been one of the most challenging and unresolved clinical questions. Several clinical, ECG and electrophysiological markers have been proposed to provide optimal risk stratification. ${ }^{5}$ However, differences in life-threatening events rates among studies and the lower risk profile demonstrated nowadays might impact these observations. ${ }^{6}$

The implantable cardioverter defibrillator (ICD) remains the most effective therapy for SCD prevention, ${ }^{7}$ however ICD complications should be considered, especially in young subjects. ${ }^{8}$

Registries assessing clinical aspects and long-term outcomes of patients with BrS are still needed to confirm data from the prior studies to identify patients at risk of SCD. In addition, the Brazilian population is not well represented in worldwide studies. The aim of the present study was to explore the association of invasive and non-invasive parameters such as ECG markers, EPS data and genetic testing with symptoms, in a cohort of type- 1 BrS patients.

\section{METHODS}

\section{Study population}

From 1999 to 2020, a total of 138 consecutive patients with type-1 BrS were included and followed-up prospectively at Instituto do Coração, Faculdade de Medicina, Universidade de Sao Paulo, in Brazil.

All the patients signed an informed consent to the study, which was conducted in accordance with the Declaration of Helsinki and had the approval of our Institutional Review Board (Protocol \#404214022).

A governmental funding (FAPESP) provided financial support for the genetic testing. A multicenter national survey on Inherited Channelopathy and Right Ventricular Cardiomyopathy was organized to provide genetic testing for patients from our and other institutions (Genetic of Brazilian Arrhythmias - GenBrA registry). All patients signed specific consent forms for genetic testing.

Patients were considered eligible if they presented with ST-segment elevation with type-1 morphology [?]2 $\mathrm{mm}$ in one or more standard precordial leads (SPL), V1 and/or V2 in the fourth intercostal space or high precordial leads (HPL), V1 and/or V2 in the second and third intercostal space, occurring either spontaneously or after provocative drug test with intravenous administration of sodium channel blockers (Ajmaline), according to the 2015 BrS Consensus. ${ }^{1}$

Subjects were classified into two groups: symptomatic (22 subjects) or asymptomatic (116 subjects), according to symptoms at the initial visit to the hospital. Symptoms were considered in cases of aborted SCD (9 subjects) or severe syncope (13 subjects). Severe syncope, presumably considered to be of arrhythmic origin, was defined as an abrupt loss of consciousness occurring without specific prodromes, syncope with seizures or a loss of consciousness during sleep with nocturnal agonal respiration. Asymptomatic group included all patients who had a non-phenocopy type-1 ECG pattern during routine examination or who underwent family screening. Seven patients were initially classified as symptomatic, but a vasovagal mechanism was evidenced during follow-up and then they were allocated in the asymptomatic group.

Baseline characteristics were obtained by periodic medical visits. The clinical variables of interest were age, gender, self-declared race, proband status, spontaneous or induced type-1 Brugada ECG pattern and 
clinical presentation at first diagnosis (symptomatic versus asymptomatic). A family history of early SCD was defined as an unexpected death before 45 years of age in the absence of known heart disease.

The following ECG parameters were accessed: PR and QRS intervals, early repolarization pattern in peripheral leads. Right ventricular outflow tract conduction delay (RVOTcd) signs were tested, including QRS fragmentation (QRS-f), aVR sign and deep S wave in lead 1. The PR and QRS intervals were measured in lead II and QRS duration was also measured in lead V2. ${ }^{9}$ QRS fragmentation was defined as 2 or more spikes within the QRS complex in leads V1 to V3. ${ }^{10}$ A positive aVR sign was defined with $\mathrm{R}$ wave [?] $3 \mathrm{~mm}$ or R/q [?] 0.75, and a deep $\mathrm{S}$ wave in lead DI was considered if $>0.1 \mathrm{mV}$ and/or duration $>40 \mathrm{~ms}$ (Figure 1). ${ }^{11-13}$ The ECG was reviewed by L.S. and F.D. to ensure the presence of a type-1 ECG and to define de ECG parameters. Occasional disagreements were solved by consensus.

All the patients underwent exercise stress testing, transthoracic echocardiogram, and most underwent electrophysiology test. Cardiac magnetic resonance imaging, coronary angiography and cardiac tomography were performed according to medical judgement.

Follow-up visits were scheduled every 6 months. Follow-up time was defined from the first diagnostic ECG to the last evaluation or death. Patients were considered to have life-threatening arrhythmic events (LAE) if they presented with sustained VT/FV, aborted SCD and appropriate ICD therapies during the follow-up period (8 subjects).

\section{Drug challenge}

The sodium channel blocker drug of choice was Ajmaline, which was administered intravenously. The protocol infusion was $10 \mathrm{mg}$ every two minutes up to a target dose of $1 \mathrm{mg} / \mathrm{kg}$. The test was considered positive if the abnormal coved type-1 ECG pattern appeared in the right precordial leads V1 and/or V2 positioned in the second, third or fourth intercostal space. Ajmaline challenge was interrupted before reaching the target dose in the following situations: QRS prolongation exceeding 30\% compared to baseline interval, an early typical Brugada type-1 ECG aspect, and in case of premature ventricular beats and/or high-degree atrioventricular block occurrence. ${ }^{1}$

\section{Electrophysiology Study}

The electrophysiology study (EPS) was performed in 92 out of 138 patients (66.7\%). Baseline measurements of conduction intervals and programmed ventricular stimulation were recorded. The programmed ventricular stimulation (PVS) was performed on two sites (right ventricular apex and right ventricular outflow tract, unless the patient had inducible ventricular tachycardia at the first location), with energy of twice the diastolic threshold, using two drive cycles (S1: 600 and $430 \mathrm{~ms}$ ) up to 3 extra stimuli (S2 to S4) with 200ms as the shortest coupling time. The EPS result was considered positive if sustained VF or VT was induced. ${ }^{14}$ Ventricular effective refractory period (VERP) was defined as the longest S1-S2 interval that fails to achieve ventricular capture. If there was conduction under $200 \mathrm{~ms}$, VERP was defined as "less than $200 \mathrm{~ms} "{ }^{10}$

\section{Implantable cardioverter defibrillator}

Implantable cardioverter defibrillator (ICD) was indicated in type-1 BrS patients with syncope presumed to be of arrhythmic origin, aborted sudden cardiac death or induced sustained VT/VF in EPS. ${ }^{7}$ In this sample, visits after ICD were scheduled for 1, 3 and 6 months, and every 6 months after that.

\section{Genetic testing}

Genetic testing with next generation sequence analysis was performed for probands with diagnosis of BrS type-1 ECG. The panel of 14 genes included: SCN5A, GPD1L, SCN10A, SCN1B, SCN2B, SCN3B, CACNA1C, CACNB2, KCND3, CACNAD2, KCNJ8, KCNE3, SLMAP, RANGRF. ${ }^{15}$ Sanger sequencing was performed for confirmation of pathogenic or likely-pathogenic variants and for genetic screening. Variants classification was based on American College of Medical Genetics (ACMG) Guidelines. ${ }^{16}$

\section{Statistical Analysis}


Categorical variables were presented as absolute values and percentages and were compared using chi-square test; Fisher test was applied as appropriate. Continuous variables were analyzed as means and standard deviations if they presented normal distribution, and as medians and interquartile intervals if abnormal. The mean differences between study groups were evaluated by calculating Student's t-test after controlling for equality of variances with the Levene's statistic.

Logistic regression was used to detect predictors of symptoms. Odds ratio and $95 \%$ confidence interval were calculated for multivariate analysis. Classical variables such as male gender, spontaneous type-1 ECG pattern and VF/VT induction were allocated in a multivariate model using a backward stepwise selection. The number of variables that could enter the multivariate analysis was limited using the $\mathrm{P}, \mathrm{m} / 10$ rule to prevent over-fitting the model.

The mean event rate per year was evaluated by the number of events occurring during the follow-up divided by the number of patients multiplied by the average duration of follow-up.

Data were analyzed with SPSS statistical package (version 20.0, SPSS, Chicago, Illinois). Significance was defined as $\mathrm{p}$ values $<0.05$.

\section{RESULTS}

\section{Study population}

A total of 138 patients were enrolled and their demographic characteristics are summarized in Table 1. Overall patients had a mean age at enrolment of $41.4+-15$ years; most patients were men $(\mathrm{n}=101 ; 73.2 \%)$ and probands $(\mathrm{n}=109 ; 79 \%)$. Spontaneous type-1 Brugada pattern was observed in $107(77.5 \%)$ patients; among overall patients, 87 out of 130 patients $(66.9 \%)$ were diagnosed using the HPL.

Programmed electrical stimulation was performed in 92 patients, 81/116 (69.8\%) in the symptomatic group and $11 / 22(50 \%)$ in the asymptomatic group ( $\mathrm{p}=0.070) ; 29$ out of 92 patients $(31.5 \%)$ met the criteria for inducibility.

Next generation sequencing was performed in 67 out of 109 probands (61.5\%). Fifteen probands $(22.4 \%)$ were carriers of a SCN5A variant (10 pathogenic and 5 likely-pathogenic variants). There were also 7 other probands carriers of SCN5A variants classified as of uncertain significance and 1 of SCN1B variant classified as of uncertain significance.

\section{Treatment}

ICD implantation was performed in 20 of $22(90.9 \%)$ from the symptomatic group, and 27 of 116 from the asymptomatic group (23.3\%). An ICD was implanted in 20 of 27 (74.1\%) of the asymptomatic patients due to a positive EPS. In the seven remaining asymptomatic patients, ICD had other reasons for indication, like family history of sudden cardiac death, anxiety or dubious syncope at initial evaluation.

\section{Follow-up Data}

The mean follow-up period for the entire study population was 75 (range 1 to 215) months. LAE occurred in 9 non-related patients and 8/9 (88.9\%) were due to appropriate ICD shocks, comprising 2 of 116 from the asymptomatic group and 7 of 22 from the symptomatic group $(\mathrm{p}<0.001)$. Death occurred because of prolonged cardiac arrest in 1/9 $(11.1 \%)$ patient in a febrile state. Therefore, the overall mean rate of LAE per year was $1.1 \%, 5.1 \%$ in the symptomatic group, which dropped to $0.27 \%$ in the asymptomatic group. Followup was significantly longer in the symptomatic patients (90 [26 to 168] months) than in the asymptomatic group (63.7 [6 to 172] months; $\mathrm{P}=0.021$ ). Two patients died during the follow-up period, the first 7 years after diagnosis, following a gunshot injury, and the second of a cholangiocarcinoma.

\section{Univariate and Multivariate Analysis}

Symptoms 
According to the univariate analysis, proband status was more frequent in the symptomatic group (100\% vs $75 \%, \mathrm{p}=0.004)$. Spontaneous type-1 classification was not different between groups $(90.9$ vs $75 \%, \mathrm{p}=0.161)$, but considering only standard leads, spontaneous pattern was more prevalent in the symptomatic than in the asymptomatic group ( $54.5 \%$ vs $27.8 ; \mathrm{p}=0.014)$. The ECG parameters were not different between groups. Inducibility tended to be more frequent among symptomatic subjects ( 54.5 vs $28.5 ; \mathrm{p}=0.094)$. Invasive and non-invasive parameters are described in Table 2.

In the multivariate analysis, parameters like VT/FV induction $(\mathrm{p}=0.173)$, male gender $(\mathrm{p}=0.363)$ and spontaneous type-1 ECG pattern $(\mathrm{p}=0.459)$ showed no independent predictive value, regardless of symptoms. (Table 3)

\section{Genetic Data}

A total of 25 type- 1 BrS patients (probands and relatives) carried SCN5A pathogenic or likely pathogenic variants. There was no difference in the clinical presentation between SCN5A mutation carriers and noncarriers $(\mathrm{p}=0.770)$. Otherwise, SCN5A carriers had a higher frequency of aVR sign $(58.3 \%$ vs $13.6 \% ; \mathrm{p}<0.001)$, $\mathrm{S}$ wave $(75 \%$ vs $48.5 \%, \mathrm{p}=0.013)$ and QRS-f $(29.2 \%$ vs $7.5 \%$; $=0.025)$. The HV interval was longer in SCN5A carriers $(66 \mathrm{~ms}$ vs $49 \mathrm{~ms} ; \mathrm{p}<0.001)$. These genotype-phenotype associations are shown in Table 4.

\section{DISCUSSION}

In a preliminary Brazilian long-term follow-up cohort of 138 Brugada syndrome patients, we did not find any variable with high sensitivity, specificity and accuracy to predict severe symptoms. Association with life threatening event might be underpowered due to the low risk profile of our population. This was the first Brazilian registry of long-term follow-up of patients with either a spontaneous or drug-induced type-1 Brugada ECG pattern. The overall characteristics of our middle-aged men population were similar to the usual presentation of $\mathrm{BrS}$ in the literature. ${ }^{17,}{ }^{18} \mathrm{It}$ is expected that proband, the first family member to look for medical assistance, might be more prevalent in the symptomatic group, which was demonstrated in our study and by other authors. ${ }^{19}$

Precise definition of spontaneous type-1 ECG pattern is somewhat dubious and has changed overtime. Curiously, in our study we demonstrated that symptoms were associated with the spontaneous pattern only if expressed in standard leads $(\mathrm{p}=0.004)$. In our registry, there is a high frequency of spontaneous type1 Brugada ECG pattern detected only when using HPL ECG technique $(\sim 70 \%)$, which is a maneuver to improve sensitivity, widely used since 2005. Despite a previous clinical comparison between with type-1 BrS detection in conventionalversus HPL ECG showed similar risk profile, ${ }^{20} \mathrm{Curcio}$ et al observed a decreased risk of arrhythmic events when type-1 Brugada pattern is defined in the HPL. ${ }^{21}$ An important limitation to this analysis is defining the real high-risk group, as we intended to refine in our methods. Traditional international registries have pointed out the symptomatic group as at higher risk, but syncope interpretation is challenging as well. ${ }^{22}$ Therefore, grouping these patients only with the category of "severe syncope" might support the high-risk profile of the group.

Many efforts have been conducted to define non-invasive and invasive markers of risk, and there is a default of reproducibility in large scale. There is some evidence that RVOTcd is the main mechanism underlying ventricular arrhythmia in BrS and this conduction abnormality can be expressed in the 12-lead ECG as AVR sign, deep S wave in lead I and QRS-f. Several reports showed its association with arrhythmic events, ${ }^{9,11,23}$ however when we analyzed these ECG parameters we found no association with symptoms.

Early repolarization in inferior leads and QRS-f had a low prevalence in our population, precluding association analysis. Even in the multicenter Prelude Study, the prevalence of QRS-f was low, although a possible marker of risk ( $\left.{ }^{\sim} 8 \%\right) \cdot{ }^{10}$ Differently, Morita et al pointed out QRS fragmentation as a risk factor for VF in both symptomatic and asymptomatic patients, while early repolarization was an important marker of VF risk recurrence. In this cohort they found a high prevalence of this ECG finding ( $~ 50 \%) .{ }^{24}$

Of note, the natural history of patients with BrS has changed over time. ${ }^{4}$ Active familiar screening and improvements in electrocardiographic recognition may contribute to the growing number of low risk patients. 
These findings could partially explain the low annual event rate of our long-term registry as compared to other groups. ${ }^{10,18}$

Patients in our study who had SCD as the first event totalized $6.5 \%$ of the overall population. Even in this group, recurrence of LAE during follow-up was not as remarkable $(22.2 \%)$ as previously described in long-term follow-up (nearly 50\%). ${ }^{22}$ The increased medical diagnosis, and the progressive improvement in survival might also be consequence of the recently introduced lifestyle change support, regularly standardized in our Institution (awareness of drugs to be avoided, exercise orientation, prompt treatment of fever, and regular visits to reinforce educational measures). ${ }^{1}$ Comparison of our profile with larger series is summarized in Table 5 .

Few symptomatic patients underwent EPS at our institution and nevertheless, our rate of inducible VF/VT was similar to the Finger Brugada registry findings, when comparing symptomatic and asymptomatic patients (46 vs 37\%, p = 0.02). ${ }^{18}$ Heterogeneity in the EPS protocol among registries, use of anesthetic drugs or sodium channel blockers during procedure could be a confounding factor to a powerful analysis. Lack of inducibility at EPS could be considered a predictor of low risk in asymptomatic subjects. In our cohort, negative predictive value in asymptomatic patients achieved $100 \%$, similar to the observations described by Sieira et al (98.3\%). ${ }^{25}$ However, if we combine the groups with and without symptoms, the negative predictive value drops to $91.8 \%$ in our casuistic and is as high as $97.5 \%$ in the FINGER registry. ${ }^{18}$ On the other hand, the positive predictive value was low (11.5\%), in agreement with other larger series. ${ }^{25}$ PRELUDE was a prospective multicenter study with homogenous enrolment criteria and has shown no predictive accuracy of sustained VT/VF inducibility by the EPS. ${ }^{10}$ The low event rate in this elegant publication also limited the accuracy and predictive value.

We also analyzed some aspects of the genotype-phenotype association. The majority of pathogenic variants reported in BrS were located in SCN5A locus, a gene that encodes the $\alpha$ subunit of the cardiac sodium channel, which accounts for less than $30 \%$ of clinically diagnosed BrS patients. Although we understand that this prevalence might be reviewed after the emerging concepts toward variants classification, ${ }^{26}$ we found pathogenic or likely pathogenic SCN5A variants in $22 \%$ of our patients, according to the ACMG criteria. ${ }^{16}$ Despite recent controversies, SCN5A is still the main gene associated with BrS. ${ }^{26}$ Studies were not elucidative to identify new variants in minor genes. ${ }^{27}$

SCN5A mutations in BrS cause loss of function of the sodium channel, resulting in delayed conduction. Slowed and discontinuous conduction has been found in computer models simulating decreased sodium current. ${ }^{28}$ The aVR sign, deep S-wave in lead 1 and QRS-f might be signals of conduction delay in the right ventricular anterior wall and these aspects were more frequent in SCN5A carriers in our registry. ${ }^{13,} 29$

Besides, patients with SCN5A variants showed a longer HV interval; PR and QRS also tended to be longer, but they were not statistically significant. These findings are also in line with data from other previous reports. ${ }^{29}$ We could not establish the association of SCN5A variants and symptoms.

Classical registries did not explore the association of SCN5A variants with these conduction delay markers, somehow related to risk. One group showed a higher aVR sign in subjects with H558R polymorphism in SCN5A. ${ }^{30}$ However, H558R polymorphism was once related to better outcomes. ${ }^{31}$

\section{Conclusions}

In summary, according to our study, patients with type- $1 \mathrm{BrS}$ had a low rate of life-threatening events. Proband status and spontaneous type 1 ECG in conventional leads were more common in the symptomatic group. Gender, family history of SCD, inducibility of ventricular tachyarrhythmias during EPS, and presence of a SCN5A variant were not predictors of symptoms. Patients with SCN5A-mediated BrS exhibited more conduction abnormalities. More studies are still necessary to better understand the gaps and to improve risk assessment in these challenging patients with Brugada Syndrome.

\section{Study limitations}


The small sample size and a low rate of LAE are important limitations to obtain robust conclusions in our cohort study for this rare disorder. Not all asymptomatic patients underwent EPS; therefore, a selection bias cannot be completely excluded. Genotype-phenotype association was studied in related subjects, also to analyze a higher number of patients, since there was a small amount of probands carrying SCN5A variants. We cannot exclude the causality findings of spontaneous type-1 BrS being associated with severe symptoms only when ECG pattern was defined in standard precordial leads position and these data need to be confirmed by other future studies aimed at this association. The mechanisms to explain this finding also deserve future considerations.

Group/Consortium Members: Author 11: Pedro Veronese, MD, PhD; Author 12: Ximena Ferrugem, MD; Author 13: Martina Pinheiro, MD; Author 14: Tan C. Wu, MD, PhD; Author 15: Muhieddine Omar Chork MD, Author 16: Cristiano Pisani, MD, PhD, Author 17: Gabriela Miana MD,; Author 18: Sissy L. Melo, MD, PhD; Author 19: Théo G. M. de Oliveira, BsC, MsC, Author 20: Carina A. Hardy, MD; Author 21: Martino Martinelli Filho, MD, PhD; Author 22: Carlos A. Pastore, MD, PhD; Author 23: Ludhmila A. Hajjar, MD, PhD; Author 24: Roberto Kalil Filho, MD, PhD;;

\section{REFERENCES}

1. Priori SG and Blomström-Lundqvist C. 2015 European Society of Cardiology Guidelines for the management of patients with ventricular arrhythmias and the prevention of sudden cardiac death summarized by co-chairs. Eur Heart J . 2015;36:2757-9.

2. Postema PG. About Brugada syndrome and its prevalence.Europace . 2012;14:925-8.

3. Sangwatanaroj S, Prechawat S, Sunsaneewitayakul B, Sitthisook S, Tosukhowong P and Tungsanga K. New electrocardiographic leads and the procainamide test for the detection of the Brugada sign in sudden unexplained death syndrome survivors and their relatives. Eur Heart J . 2001;22:2290-6.

4. Casado-Arroyo R, Berne P, Rao JY, Rodriguez-Mañero M, Levinstein M, Conte G, Sieira J, Namdar M, Ricciardi D, Chierchia GB, de Asmundis C, Pappaert G, La Meir M, Wellens F, Brugada J and Brugada P. Long-Term Trends in Newly Diagnosed Brugada Syndrome: Implications for Risk Stratification. J Am Coll Cardiol . 2016;68:614-623.

5. Brugada J, Campuzano O, Arbelo E, Sarquella-Brugada G and Brugada R. Present Status of Brugada Syndrome: JACC State-of-the-Art Review.J Am Coll Cardiol . 2018;72:1046-1059.

6. Vutthikraivit W, Rattanawong P, Putthapiban P, Sukhumthammarat W, Vathesatogkit P, Ngarmukos T and Thakkinstian A. Worldwide Prevalence of Brugada Syndrome: A Systematic Review and Meta-Analysis. Acta Cardiol Sin . 2018;34:267-277.

7. Al-Khatib SM, Stevenson WG, Ackerman MJ, Bryant WJ, Callans DJ, Curtis AB, Deal BJ, Dickfeld T, Field ME, Fonarow GC, Gillis AM, Granger CB, Hammill SC, Hlatky MA, Joglar JA, Kay GN, Matlock DD, Myerburg RJ and Page RL. 2017 AHA/ACC/HRS guideline for management of patients with ventricular arrhythmias and the prevention of sudden cardiac death: Executive summary: A Report of the American College of Cardiology/American Heart Association Task Force on Clinical Practice Guidelines and the Heart Rhythm Society. Heart Rhythm . 2018;15:e190-e252.

8. Gonzalez Corcia MC, Sieira J, Pappaert G, de Asmundis C, Chierchia GB, La Meir M, Sarkozy A and Brugada P. Implantable Cardioverter-Defibrillators in Children and Adolescents With Brugada Syndrome. J Am Coll Cardiol . 2018;71:148-157.

9. Ohkubo K, Watanabe I, Okumura Y, Ashino S, Kofune M, Nagashima K, Kofune T, Nakai T, Kunimoto S, Kasamaki Y and Hirayama A. Prolonged QRS duration in lead V2 and risk of life-threatening ventricular Arrhythmia in patients with Brugada syndrome. Int Heart J . 2011;52:98-102.

10. Priori SG, Gasparini M, Napolitano C, Della Bella P, Ottonelli AG, Sassone B, Giordano U, Pappone C, Mascioli G, Rossetti G, De Nardis R and Colombo M. Risk stratification in Brugada syndrome: results 
of the PRELUDE (PRogrammed ELectrical stimUlation preDictive valuE) registry.J Am Coll Cardiol . 2012;59:37-45.

11. Babai Bigi MA, Aslani A and Shahrzad S. aVR sign as a risk factor for life-threatening arrhythmic events in patients with Brugada syndrome. Heart Rhythm . 2007;4:1009-12.

12. Calò L, Giustetto C, Martino A, Sciarra L, Cerrato N, Marziali M, Rauzino J, Carlino G, de Ruvo E, Guerra F, Rebecchi M, Lanzillo C, Anselmino M, Castro A, Turreni F, Penco M, Volpe M, Capucci A and Gaita F. A New Electrocardiographic Marker of Sudden Death in Brugada Syndrome: The S-Wave in Lead I. J Am Coll Cardiol . 2016;67:1427-1440.

13. Rolf S, Bruns HJ, Wichter T, Kirchhof P, Ribbing M, Wasmer K, Paul M, Breithardt G, Haverkamp W and Eckardt L. The ajmaline challenge in Brugada syndrome: diagnostic impact, safety, and recommended protocol.Eur Heart J . 2003;24:1104-12.

14. Antzelevitch C, Brugada P, Borggrefe M, Brugada J, Brugada R, Corrado D, Gussak I, LeMarec H, Nademanee K, Perez Riera AR, Shimizu W, Schulze-Bahr E, Tan H and Wilde A. Brugada syndrome: report of the second consensus conference. Heart Rhythm . 2005;2:429-40.

15. Sarquella-Brugada G, Campuzano O, Arbelo E, Brugada J and Brugada R. Brugada syndrome: clinical and genetic findings. Genet Med . 2016;18:3-12.

16. Richards S, Aziz N, Bale S, Bick D, Das S, Gastier-Foster J, Grody WW, Hegde M, Lyon E, Spector E, Voelkerding K, Rehm HL and Committee ALQA. Standards and guidelines for the interpretation of sequence variants: a joint consensus recommendation of the American College of Medical Genetics and Genomics and the Association for Molecular Pathology. Genet Med . 2015;17:405-24.

17. Milman A, Andorin A, Gourraud JB, Sacher F, Mabo P, Kim SH, Maeda S, Takahashi Y, Kamakura T, Aiba T, Conte G, Juang JJM, Leshem E, Rahkovich M, Hochstadt A, Mizusawa Y, Postema PG, Arbelo E, Huang Z, Denjoy I, Giustetto C, Wijeyeratne YD, Napolitano C, Michowitz Y, Brugada R, Casado-Arroyo R, Champagne J, Calo L, Sarquella-Brugada G, Tfelt-Hansen J, Priori SG, Takagi M, Veltmann C, Delise P, Corrado D, Behr ER, Gaita F, Yan GX, Brugada J, Leenhardt A, Wilde AAM, Brugada P, Kusano KF, Hirao K, Nam GB, Probst V and Belhassen B. Age of First Arrhythmic Event in Brugada Syndrome: Data From the SABRUS (Survey on Arrhythmic Events in Brugada Syndrome) in 678 Patients. Circ Arrhythm Electrophysiol . 2017;10.

18. Probst V, Veltmann C, Eckardt L, Meregalli PG, Gaita F, Tan HL, Babuty D, Sacher F, Giustetto C, Schulze-Bahr E, Borggrefe M, Haissaguerre M, Mabo P, Le Marec H, Wolpert C and Wilde AA. Long-term prognosis of patients diagnosed with Brugada syndrome: Results from the FINGER Brugada Syndrome Registry. Circulation . 2010;121:635-43.

19. Sieira J, Conte G, Ciconte G, Chierchia GB, Casado-Arroyo R, Baltogiannis G, Di Giovanni G, Saitoh Y, Juliá J, Mugnai G, La Meir M, Wellens F, Czapla J, Pappaert G, de Asmundis C and Brugada P. A score model to predict risk of events in patients with Brugada Syndrome.Eur Heart J . 2017;38:1756-1763.

20. Miyamoto K, Yokokawa M, Tanaka K, Nagai T, Okamura H, Noda T, Satomi K, Suyama K, Kurita T, Aihara N, Kamakura S and Shimizu W. Diagnostic and prognostic value of a type 1 Brugada electrocardiogram at higher (third or second) V1 to V2 recording in men with Brugada syndrome.Am J Cardiol . 2007;99:53-7.

21. Curcio A, Mazzanti A, Bloise R, Monteforte N, Indolfi C, Priori SG and Napolitano C. Clinical Presentation and Outcome of Brugada Syndrome Diagnosed With the New 2013 Criteria. J Cardiovasc Electrophysiol . 2016;27:937-43.

22. Sacher F, Probst V, Maury P, Babuty D, Mansourati J, Komatsu Y, Marquie C, Rosa A, Diallo A, Cassagneau R, Loizeau C, Martins R, Field ME, Derval N, Miyazaki S, Denis A, Nogami A, Ritter P, Gourraud JB, Ploux S, Rollin A, Zemmoura A, Lamaison D, Bordachar P, Pierre B, Jaïs P, Pasquié JL, 
Hocini M, Legal F, Defaye P, Boveda S, Iesaka Y, Mabo P and Haïssaguerre M. Outcome after implantation of a cardioverter-defibrillator in patients with Brugada syndrome: a multicenter study-part 2. Circulation . 2013;128:1739-47.

23. Tse G, Gong M, Meng L, Wong CW, Georgopoulos S, Bazoukis G, Wong MCS, Letsas KP, Vassiliou VS, Xia Y, Baranchuk AM, Yan GX and Liu T. Meta-analysis of T. J Electrocardiol . 2018;51:396-401.

24. Morita H, Watanabe A, Kawada S, Miyamoto M, Morimoto Y, Nakagawa K, Nishii N, Nakamura K and Ito H. Identification of electrocardiographic risk markers for the initial and recurrent episodes of ventricular fibrillation in patients with Brugada syndrome. J Cardiovasc Electrophysiol . 2018;29:107-114.

25. Sieira J, Conte G, Ciconte G, de Asmundis C, Chierchia GB, Baltogiannis G, Di Giovanni G, Saitoh Y, Irfan G, Casado-Arroyo R, Juliá J, La Meir M, Wellens F, Wauters K, Van Malderen S, Pappaert G and Brugada P. Prognostic value of programmed electrical stimulation in Brugada syndrome: 20 years experience. Circ Arrhythm Electrophysiol . 2015;8:777-84.

26. Denham NC, Pearman CM, Ding WY, Waktare J, Gupta D, Snowdon R, Hall M, Cooper R, Modi S, Todd D and Mahida S. Systematic re-evaluation of SCN5A variants associated with Brugada syndrome. $J$ Cardiovasc Electrophysiol . 2019;30:118-127.

27. Walsh R and Wilde AAM. SCN5A variants in Brugada syndrome: True, true false, or false true. $J$ Cardiovasc Electrophysiol . 2019;30:128-131.

28. Bébarová M, O'Hara T, Geelen JL, Jongbloed RJ, Timmermans C, Arens YH, Rodriguez LM, Rudy $\mathrm{Y}$ and Volders PG. Subepicardial phase 0 block and discontinuous transmural conduction underlie right precordial ST-segment elevation by a SCN5A loss-of-function mutation. Am J Physiol Heart Circ Physiol . 2008;295:H48-58.

29. Yamagata K, Horie M, Aiba T, Ogawa S, Aizawa Y, Ohe T, Yamagishi M, Makita N, Sakurada H, Tanaka T, Shimizu A, Hagiwara N, Kishi R, Nakano Y, Takagi M, Makiyama T, Ohno S, Fukuda K, Watanabe H, Morita H, Hayashi K, Kusano K, Kamakura S, Yasuda S, Ogawa H, Miyamoto Y, Kapplinger JD, Ackerman MJ and Shimizu W. Genotype-Phenotype Correlation of. Circulation . 2017;135:2255-2270.

30. Lizotte E, Junttila MJ, Dube MP, Hong K, Benito B, DE Zutter M, Henkens S, Sarkozy A, Huikuri HV, Towbin J, Vatta M, Brugada P, Brugada J and Brugada R. Genetic modulation of brugada syndrome by a common polymorphism. J Cardiovasc Electrophysiol . 2009;20:1137-41.

31. Matsumura H, Nakano Y, Ochi H, Onohara Y, Sairaku A, Tokuyama T, Tomomori S, Motoda C, Amioka M, Hironobe N, Toshishige M, Takahashi S, Imai K, Sueda T, Chayama K and Kihara Y. H558R, a common SCN5A polymorphism, modifies the clinical phenotype of Brugada syndrome by modulating DNA methylation of SCN5A promoters. J Biomed Sci . 2017;24:91.

\section{FIGURE LEGENDS}

Figure 1. Example of standard ECG in a type-1 BrS patient (\# 118), presenting with deep/large $S$ wave in lead I and AVR sign.

\section{TABLES}

Table 1 Baseline Characteristics of the entire population.

Variable

Age at enrollment (years), mean \pm SD Proband, $\mathrm{n}$

(\%) Male, n (\%) Ethnicity White

Black

Yellow

Brown

Family history of SCD, n (\%)
TOTAL $(\mathbf{N}=138)$

41.4+/- 14.8109 (79) 101 (73.2) 97 (70.3) 2 (1.4)

$10(7.2) 29(21)$

$67(48.6)$ 
Spontaneous type-1 BrS pattern, n (\%)

In standard leads, $\mathrm{n} / \mathrm{N}(\%)$

Symptoms, n (\%)

Syncope, n/N (\%)

aSCD, n/N (\%)

EPS, n $(\%)$

Inducibility rate, $\mathrm{n} / \mathrm{N}(\%)$
$107(77.5)$

$43 / 130(33.1)$

$22(15.9)$

$13 / 22(59.1)$

$9 / 22(40.9)$

$92(66.7)$

$29 / 92(31.5)$

aSCD: aborted sudden cardiac death, BrS: Brugada syndrome; EPS: electrophysiological study, ICD: implantable cardiac defibrillator, SCD: sudden cardiac death;,SD: standard deviation.

Table 2 Invasive and non-invasive parameters according to symptoms

\begin{tabular}{llll}
\hline Variable & Groups & Groups & $\mathrm{p}$ \\
\hline & Asymptomatic & Symptomatic & \\
& $\mathrm{n}=116$ & $\mathrm{n}=22$ & \\
Age at enrollment (years), mean $\pm \mathrm{SD}$ & $41.4 \pm 15$ & $41.7 \pm 14$ & $0.910^{* *}$ \\
Male gender & $81(69.8)$ & $20(90.9)$ & $0.063^{*}$ \\
Proband & $87(75)$ & $22(100)$ & $0.004^{*}$ \\
FH of SCD & $55(47.4)$ & $12(54.5)$ & 0.539 \\
Spontaneous pattern & $87(75)$ & $20(90.9)$ & $0.161^{*}$ \\
Conventional ECG & $30 / 108(27.8)$ & $12 / 22(54.5)$ & 0.014 \\
QRS width in V2 & $104 \pm 19$ & $108 \pm 19$ & $0.286^{* *}$ \\
QRS-F & $11 / 107(10.3)$ & $4 / 22(18.2)$ & $0.286^{*}$ \\
AVR sign & $22 / 108(20.4)$ & $7 / 22(31.8)$ & $0.265^{*}$ \\
S in lead I & $63 / 108(58.3)$ & $16 / 22(72.7)$ & 0.208 \\
Inferior ER & $9 / 107(8.4)$ & $1 / 22(4.5)$ & $1.000^{*}$ \\
VF/VT induction & $23 / 81(28.4)$ & $6 / 11(54.5)$ & $0.094^{*}$ \\
eVRP < 200ms & $12 / 70(17.1)$ & $1 / 8(12.5)$ & $1.000^{*}$ \\
Appropriate ICD shocks & $2 / 27(7.4)$ & $6 / 20(30)$ & $0.057^{*}$ \\
LAE during follow-up & $2(1.7)$ & $7(31.8)$ & $<0.001^{*}$ \\
SCN5A+ & $20 / 76(26.3)$ & $5 / 17(29.4)$ & $0.770^{*}$ \\
Mean event rate per year, \% & 0.27 & 5.1 & \\
\hline
\end{tabular}

Chi-square test, * Fisher's exact test, ** Student's t-test;

ER : early repolarization; eVRP : effective ventricular refractory period; QRS-f : QRS fragmentation in precordial leads; FH of SCD : family history of sudden cardiac death,LAE : life-threatening arrhythmic event, SCN5A + carriers of pathogenic or likely pathogenic variants.

Table 3 Multivariate model for symptoms and clinical signs

\begin{tabular}{lclll}
\hline Variable & OR & 95\% confidence interval & 95\% confidence interval & P \\
\hline & & Lower & Upper & \\
Male & 1.12 & 0.042 & 3.311 & 0.375 \\
Spontaneous type 1 & 1.11 & 0.050 & 3.913 & 0.465 \\
VT/VF inducibility & 0.68 & 0.101 & 1.465 & 0.160 \\
\hline
\end{tabular}

Multivariate analysis according to symptoms. 
Table 4 Genotype-phenotype association in probands and relatives according to SCN5A variants identified.

\begin{tabular}{llll}
\hline Variable & Genetic testing & Genetic testing & p \\
\hline & No $(\mathbf{N}=\mathbf{6 8})$ & Yes $(\mathbf{N}=\mathbf{2 5})$ & \\
Spontaneous type-1, n (\%) & $51(75)$ & $16(66.7)$ & 0.430 \\
Symptoms & $12(17.6)$ & $5(20.8)$ & $0.764^{*}$ \\
Syncope, n (\%) & $5(7.4)$ & $5(20.8)$ & $0.120^{*}$ \\
SCD, n (\%) & $7(10.3)$ & $0(0)$ & $0.184^{*}$ \\
FH of SCD, n (\%) & $36(52.9)$ & $18(72)$ & 0,090 \\
PR (ms), mean \pm SD & $168 \pm 26$ & $182 \pm 42$ & $0.049^{* *}$ \\
QRS duration DII (ms), mean \pm SD & $105 \pm 18$ & $110 \pm 21$ & $0.336^{* *}$ \\
QRS duration in V2 (ms), mean \pm SD & $105 \pm 18.4$ & $107 \pm 20.7$ & $0.696^{* *}$ \\
aVR sign, n/N (\%) & $9 / 66(13.6)$ & $13 / 23(56.5)$ & $<0.001$ \\
S-wave in lead I, n/N (\%) & $32 / 66(48.5)$ & $18 / 23(78.3)$ & 0.015 \\
ER peripheral leads, n/N (\%) & $7 / 65(10.8)$ & $1 / 23(4.3)$ & 0.675 \\
QRS-f, n/N (\%) & $5 / 65(7.7)$ & $7 / 23(30.4)$ & $0.012^{*}$ \\
Inducible VT/VF, n/N (\%) & $18 / 48(37.5)$ & $6 / 16(37.5)$ & 1.000 \\
HV interval, mean \pm SD & $49 \pm 7$ & $67 \pm 16$ & $<\mathbf{0 . 0 0 1 * *}$ \\
eVRP $<200 m s, n / N ~(\%)$ & $7 / 38(18.4)$ & $2 / 16(12.5)$ & $0.709^{*}$ \\
LAE, n/N (\%) & $3 / 27(11.1)$ & $3 / 10(30)$ & $0.313^{*}$ \\
\hline
\end{tabular}

Chi-square test, ${ }^{*}$ Fisher's exact test, ${ }^{* *}$ Student's t-test;ER $=$ early repolarization; $\mathbf{e V R P}=$ effective ventricular refractory period; FH of SCD: family history of sudden cardiac death; QRS-f: QRS fragmentation in precordial leads;SCN5A + carriers of pathogenic or likely pathogenic variants.

Table 5. Comparative data from large registries and GenBrA.

\begin{tabular}{|c|c|c|c|c|c|}
\hline & Brugada et al ${ }^{16}$ & FINGER $^{11}$ & PRELUDE $^{17}$ & Sieira et al ${ }^{18}$ & Letsas et $\mathrm{al}^{15}$ \\
\hline Type of study & $\mathrm{SC}$ & $\mathrm{MC}$ & $\mathrm{MC}$ & $\mathrm{SC}$ & $\mathrm{SC}$ \\
\hline Year of publication & 2003 & 2010 & 2012 & 2015 & 2019 \\
\hline Total patients & 547 & 1029 & 308 & 404 & 111 \\
\hline Mean follow-up (mo) & 24 & 31.9 & 36 & 74 & 55.2 \\
\hline Male, n (\%) & $408(74.6)$ & $745(72)$ & $247(80)$ & $235(58.2)$ & $86(77.5)$ \\
\hline Mean Age & 41 & 45 & 47 & 43.2 & 45.3 \\
\hline Probands status, n (\%) & NA & $808(78)$ & NA & $129(31.9)$ & \\
\hline Spontaneous type-1, n (\%) & $391(71.5)$ & $468(45)$ & $171(56)$ & $75(18.6)$ & $49(44.14)$ \\
\hline Symptoms, n (\%) Syncope SCD & $124(22.7) 0$ & $313(30) 62(6)$ & $65(21) 0$ & $114(28.6) 17(4.2)$ & $37(33.3)-$ \\
\hline Inducible VF/VT, n/N (\%) & $163 / 245(66.5)$ & $262 / 638(41.1)$ & $126 / 308(41)$ & $73 / 404(18.1)$ & $32 / 59(54.2)$ \\
\hline $\mathrm{ICD}, \mathrm{n}(\%)$ & $177(32.4)$ & $551(53.5)$ & $137(44)$ & $168(41.6)$ & $34(30.6)$ \\
\hline Annual event rate, $\%$ & 4.1 & 1.6 & 1.5 & 0.9 & 1.4 \\
\hline
\end{tabular}

ICD : implantable cardiac defibrillator, MC : multicenter study, NA : not available, SC : single center, SCD : sudden cardiac death, VF/VT : ventricular fibrillation or tachycardia. 